\title{
Morphological Study of the Lingual Papillae in Mellivora
}

\section{capensis Tongue}

\author{
Abdul-Hadi Sallal Mohammed, Salih Khames Haider and Rokaya Ali Salman \\ Department of Medical Laboratory, Foundation of Technical Education, College of Health and Medical Technology, Kufa, Najaf \\ 00964, Iraq
}

\begin{abstract}
Background: The present study was conducted on the three Mellivora tongues, and the tongue was divided into three portions, apex, body and base. The tongue was tapered at the apex, wider in the middle and had elevation at the base, which termed torus linguae. The tongue is triangular in shape, and the length of tongue ranged between $58-60 \mathrm{~mm}$. The dorsum linguae of this wild animal were characterized by presence of median groove. Methods: After killing, the Mellivora capensis were skinned and the heads were dissected to approach the tongue. The tongues were prepared for morphometric and morphological studies. Results: The morphological study revealed five types of lingual papillae (filiform, conical, fungiform, circumvallate and foliate). The filiform were numerous and scattered on the entire dorsal and lateral surfaces. They were thread like projections, and found in different forms (single, bifurcated, trifurcated and serrated end). The conical papillae were found among the filiform papillae with rounded ends. The fungiform papillae have dome or mushroom-shapes and distributed at the apex of the tongue. The circumvallate papillae were globular or circular shapes and surrounded by trench and located at posterior of tongue between the end of body and torus linguae. The foliate papillae were found on the posterio-lateral surface of the tongue, ridges-shaped and were separated by grooves. Conclusion: The present study showed five types of dorsal lingual papillae: filiform, conical, fungiform, cicumvallate and foliate.
\end{abstract}

Key words: Mellivora capensis, tongue, wild animals tongue, lingual papillae, torus linguae.

\section{Introduction}

The dorsal surface of mammalian tongue is consist of five types of lingual papillae, including filiform, fungiform, circumvallate and foliate papillae, which were distributed on the dorsal surface of the tongue [1].

Many investigators has described the histo-morphological structure of the lingual surface of the various domestic mammals especially ruminants such as cow [2], buffalo [3], one-humped camel [4], goat [5] and lesser mouse deer [6].

The morphology and anatomical observations of dorsal surfaces of the tongues in domestic mammals and its lingual papillae was studied in many textbooks of histology [7, 8]. There are numerous works about morphogenesis of lingual papillae in different laboratory animals such rabbits [9, 10] and mouse [11].

Corresponding author: Abdul-Hadi Sallal Mohammed, Ph.D, professor, research fields: histology sciences. E-mail: al_hadi2002@yahoo.com.
The scanning electron microscopic studies conducted on developing gustatory papillae in human tongue [12].

The scientific classification of Mellivora capensis (honey badger): kingdom: Animalia; phylum: Chordate; class: Mammalian; order: Carnivora; family: Mustelidae; subfamily: Mellivorinae; genus: Mellivora and species: Capensis.

The geographical distribution of wild animal in Iraqi is around agriculture regions such as Baghdad, Basrah, Diwanyia and Najaf cities. These wild animals are omnivorous, feed on reptiles, birds, amphibians, insects (especially larvae of honey bees) and roots of plants [13]. M. capenesis is mostly present in Africa and south-western Asia [14].

The aim of present study focused the light on the gross-morphological description of the lingual papillae that was found on the dorsum of Mellivora capensis tongues, due to little literature reviews about this wild 
animal.

\section{Materials and Methods}

Three females of Mellivora capensis (Fig. 1) was killed by farmers in the agriculture regions around Diwanyia and Najaf provinces.

The mean weight of animals was $18 \mathrm{~kg}$ and the age of these animals was 3-4 years old estimated according to the dentation method [14]. The tongues were removed from their attachment with pharynx, and then prepared for morphometric and morphological studies, including: measurement of the length, width and thickness of tongues at different regions (the apex, body and root), and measurement the length of median grooves and torus linguae as well as recording the width of torus linguae at the base of tongue. The morphological study have been done on the dorsal surfaces and lateral surfaces of the tongues by using the dissecting microscope (Olympus, Japan), to demonstrate and describe the morphology of each lingual papillae in this wild animal.

\section{Results}

The Mellivora capensis tongue was triangular-shaped, tapered at the apex, wide in the middle and had elevation at the base which represented the torus linguae. The length of tongue from apex to base ranged $58-60 \mathrm{~mm}$; the width at the apex and the base were $16-17 \mathrm{~mm}$ and $21-22.5 \mathrm{~mm}$.

The thickness of tongue at apex, middle and base were 2.8-3.1, 16.5-17.6, 18.7-19.6 mm, respectively (Table 1).

The dorsum of the Mellivora capensis tongue was boarder than ventral surface, and the dorsal surface was characterized by median groove (Fig. 2) which divided the dorsum of tongue into equal portions.

The length of median groove and the length and width of the torus linguae are ranged 31-33.3, 21.5-23.1 and 16.9-17.1 mm, respectively (Table 2).

The dorsal and the lateral surfaces of the tongue were rough due to the mechanical and gustatory lingual papillae that projected from dorsal and lateral surfaces, while the ventral surface of tongue was smooth and free of lingual papillae. The morphological study revealed five types of lingual papilla, the most common type was filiform papillae (Fig. 3).

The filiform lingual papillae were distributed over the whole dorsum of tongue and lateral sides from the apex to the base. They were wide and large in the base, slender and thin at the middle and tapered at the ends. They are found in different forms, either single, bifurcated or trifurcated (Figs. 4 and 5) and serrated-shapes (Fig. 4).

Figs. 3 and 6 showed the fungiform papillae ,which appeared large and similar to mushroom and appeared dome-shape that enclosed by groove. They were situated singly among the filiform papillae.

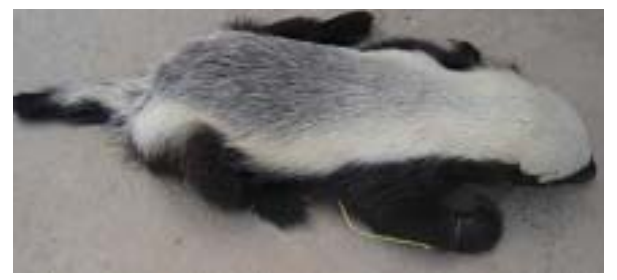

Fig. 1 Mellivora capensis.

Table 1 Dimensions of the Mellivora capensis tongue (mm).

\begin{tabular}{ll}
\hline Parameters & Range \\
\hline Length of tongue & $58-60$ \\
Width of tongue at the apex & $16-17$ \\
Width of tongue at the middle & $27.3-28.2$ \\
Width of tongue at the base & $21-22.5$ \\
Thickness of tongue at the apex & $2.8-3.1$ \\
Thickness of tongue at the middle & $16.5-17.6$ \\
Thickness of tongue at the base & $18.7-19.6$ \\
\hline
\end{tabular}

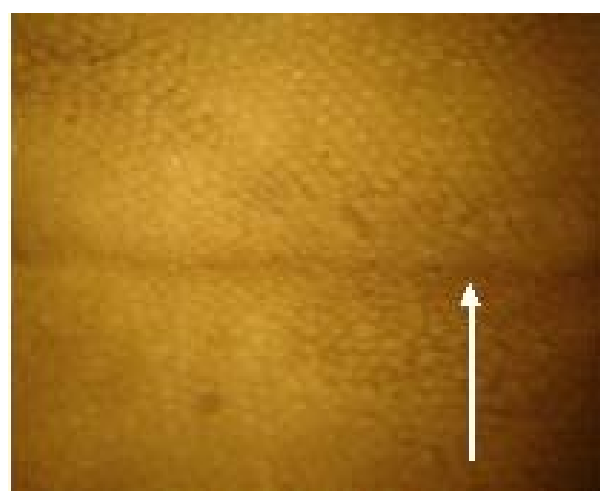

Fig. 2 The median groove located at the dorsum surface of Mellivora tongue (arrow). 
Table 2 Dimensions of median groove and torus linguae of Mellivora capensis (mm).

\begin{tabular}{ll}
\hline Parameters & Range \\
\hline Length of median groove & $31.6-33.3$ \\
Length of torus linguae at the base & $21.5-23.1$ \\
Width of torus linguae & $16.9-17.1$ \\
\hline
\end{tabular}

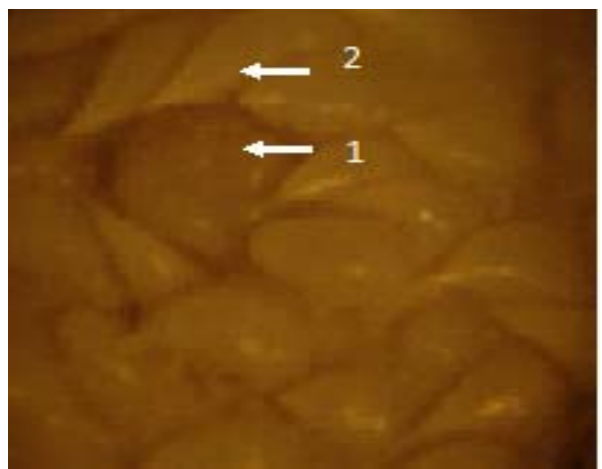

Fig. 3 Dorsal surface of Mellivora tongue. 1: fungiform; 2: filiform papillae.

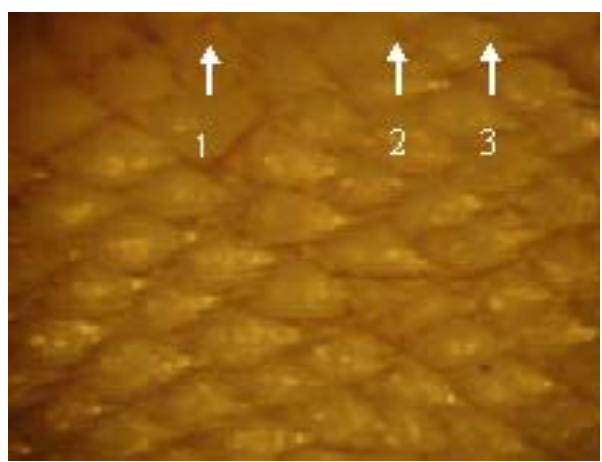

Fig. 4 Distribution of Filiform papillae on the dorsum lingua of Mellivora. 1: serrated; 2: bifurcated; 3: trifurcated.

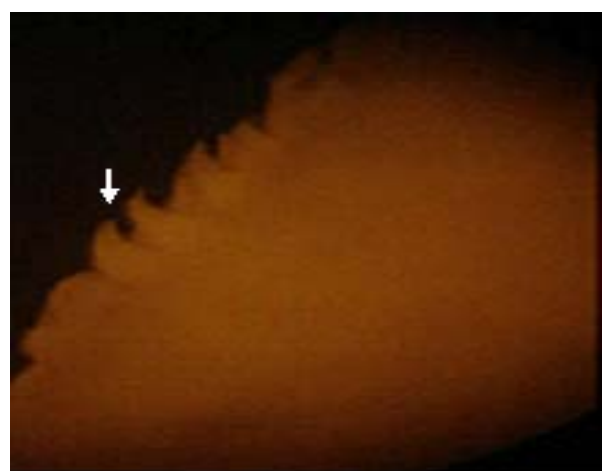

Fig. 5 Filiform papilla (arrow) located at posterio-lateral edge of Mellivora tongue.

The circumvallate lingual papillae (Fig. 7) in the present study appeared globular, or circular in shape and surrounded by circular groove. These kinds of papillae were situated in the posterior portion of the tongue anterior to the torus linguae. The foliate papillae were observed on both sides (right and left) of the tongue, especially on the posterio-lateral surface, in an inter-digitation pattern, like ridges and separated by shallow grooves (Fig. 8).

The conical lingual papillae (Fig. 7) had a round terminal ends, located among the filiform lingual papillae at the dorsal and lateral surfaces, and scattered on the entire lingual dorsum.

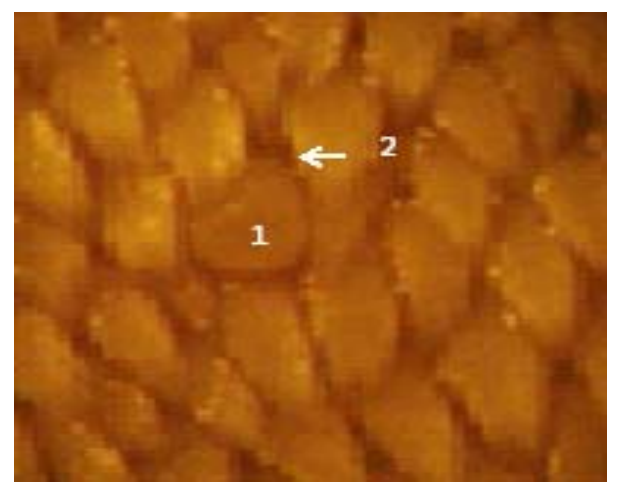

Fig. 6 Lingual dorsum of Mellivora. 1: fungiform papilla; 2: groove surrounded the papilla.

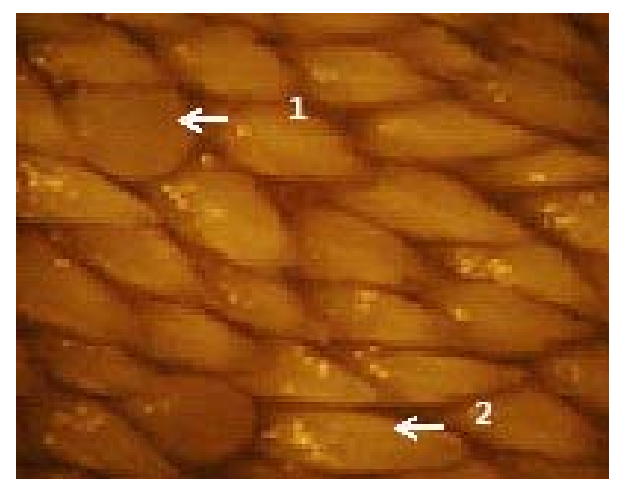

Fig. 7 Dorsum lingua of Mellivora with. 1: circumvallate papilla; 2: conical papilla.

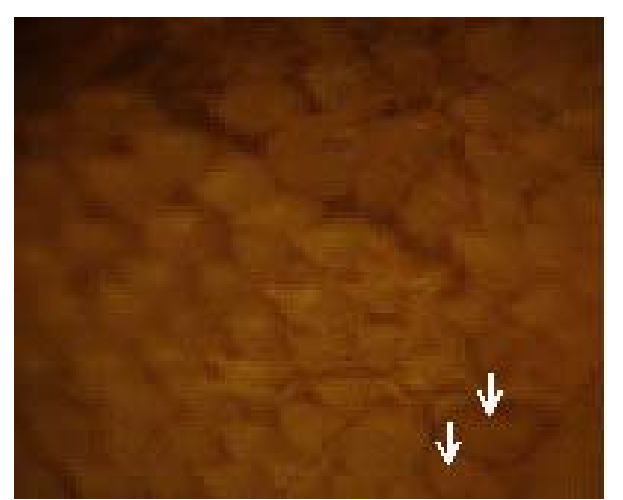

Fig. 8 The foliate papillae (arrows) are situated on postrio-lateral surface of Mellivora toung. 


\section{Conclusions}

The present study showed five kinds of dorsal lingual papillae, filiform, conical, fungiform, circumvallate and foliate papillae in the Mellivora capensis. The distribution and arrangement of filiform papillae give the tongue a rough surface adapted for grinding and movement of food.

The present study revealed that the conical papillae were similar to those present in ruminants. The present study was corresponded with previous studies $[15,16]$ which mentioned lingual elevation in domestic ruminants (goats and cattle), in addition to filiform, conical and lenticular papillae. The morphology and characteristic features of fungiform papillae were large and pyramidal or dome-shaped, scattered at the apex of the tongue, and these observations coincide with previous studies $[17,18]$ in the lesser mouse deer and several species of primates.

The circumvallate papillae of Mellivora capensis were enclosed by circular groove, appeared rounded and embedded in lingual epithelium, unlike the equine and bovine circumvallate papillae, which were composed of a primary papillae and divided into several secondary papillae by inter mediate groove. While in bovine circumvallate papillae, there were twin papillae and sometimes they were surrounded by a primary groove [2].

The foliate papillae were situated on the latero-posterior portion, and resemble to ridges which were separated by grooves. This type of papillae were well developed in the rabbit, pig and horse, but extremely small in the dog, rudimentary in the cat and completely absent in ruminants except for cattle [16, 18, 19].

The variations in some mammalian lingual papillae may be concerned with the feeding habits and the type of food eating. Mellivora capensis are omnivorous feed on the vertebrates such as birds, reptiles and larvae of honey bees and roots of plants. This feeding may play an important role in the typical characteristic features of lingual papillae in this animals.

\section{References}

[1] H.S. Jung, K. Akita, J.Y. Kim, Spacing pattern on tongue surface, gustatory papillae, Int. J. Dev. Biol. 48 (2-3) (2004) 157-161.

[2] P. de-Paz Cabello, C.A. Chamorro, J. Sandoval, M. Ferndoz, Comparative scanning electron microscopic study of the lingual papillae in two species of domestic mammals (Equus caballus and Bos taurus). II Mechanical papillae, Acta. Anat. 132 (2) (1988) 120-123.

[3] G. Scala, G.V. Pelagalh, A. Vittoria, P. de Girolamo, Morphological structure of lingual papillae in the buffalo Bubalus bubalus, Anat. Histo. Embryol. 22 (1993) 264-272.

[4] M.A. Qayyum, J.A. Fatani, A.M. Mohajir, Scanning electron microscopic study of the lingual papillae of the one-humped camel , Camelus dromedaries, J. Anat. 160 (1988) 21-26.

[5] C.O. Lghokwe, C. Oklie, The morphological observations of some lingual papillae in the prenatal and prepuberal stages of red sokoto Goats (Capra hircus), Int. J. Morphol. 27 (1) (2009) 145-150.

[6] S. Agungpriyono, J. Yamada, N. Kitamura, C. Nisa, K. Sigit, Y. Yamamoto, Morphology of lingual papillae in lesser mouse deer (Tragulus Javanicus), J. Anat. 187 (Pt 3) (1995) 635-640.

[7] A. Ham, D. Cormack, Textbook of Histology, 8th ed., Lippincott, Philadelphia and Toronto, 1979, pp. 647-650.

[8] H. Dellman, Textbook of Veterinary Histology, Lea and Febiger, Philadelphia, 2006, pp. 477-483.

[9] M. Kuwalik, The development of the mucous membrane of the tongue with emphasis on the development of fungiform papillae in the prenatal life of the rabbit, Electron. J. Pal. Agric. Univ. Ser. Vet. Med. 8 (4) (2005a) 4.

[10] M. Kuwalik, Morphology of the mucous membrane of the tongue with special emphasis on the papillae in the period from one-day to six month of postnatal life in the rabbit, Acta. Sci. Pal. Med. Vet. 4 (2005b) 47-58.

[11] U. Cássia, W. li-sei, K.Jr. Bruno, Y.K. Luciane, S. Marisa, C.T. Roberto, Scanning electron microscopic study of the dorsal surface of the tongue of the mouse, Ann. Anat. 177 (6) (1995) 569-572.

[12] M. Witt, K. Reutter, Scanning electron microscopic studies of developing gustatory papillae in human, Chem. Senses. 22 (6) (1997) 601-612.

[13] K. Begg, C. Begg, A. Abramov, Mellivora capensis, in: IUCN Red List of Threatened Species, 2008, p. 1.

[14] G. Baryshnikov, A new subspecies of the honey badger Mellivora capensis from central Asia, Acta Theriologica 45 (1) (2008) 45-55.

[15] J. Yamada, N. Calingasan, N. Kitamura, T. Yamashita, 
Comparative scanning electron microscopic study of the lingual papillae of some domestic animals, Philippine Journal of Veterinary Med. 22 (1983) 1-6.

[16] R. Nickel, W.O. Sack, E. Sieferle, The Viscera of the Domestic Mammals. 2nd ed., Verlag Paul Parey, Berlin, 1979, pp. 10-15.

[17] S. Agungpriyono, J. Yamada, N. Kitamura, C. Nisa, K. Sigit, Y. Yamamoto, Morphology of the dorsal lingual papillae in the lesser mouse deer, Tragulus javanicus,
Journal of Anatomy, 187 (Pt 3) (1995) 635-640.

[18] H.O. Hofer, A. Castenholz, H. Zöltzer, The sublingua and tongue of Tupaia (scandentia, mammalian): A scanning electron microscope study, Folia Primatologica, 60 (4) (1993) 185-194.

[19] A.W. Stinson, M.L. Calhoun, Digestive System, in: H.D. Dellmann, E.M. Brown (Eds.), Textbook of Veterinary Histology, Lea and Febiger, Philadelphia, 1993, pp. 207-264. 